\title{
Smart Precision based Agriculture using Sensors
}

\author{
K. Lakshmisudha \\ Assistant Professor \\ Dept. of Information \\ Technology, \\ SIES GST \\ $\operatorname{Nerul}(\mathrm{E})$.
}

\author{
Swathi Hegde \\ BE-IT \\ SIES GST \\ $\operatorname{Nerul}(E)$.
}

\author{
Neha Kale \\ BE-IT \\ SIES GST \\ $\operatorname{Nerul}(\mathrm{E})$.
}

\author{
Shruti lyer \\ BE-IT \\ SIES GST \\ $\operatorname{Nerul}(E)$.
}

\begin{abstract}
Smart precision based agriculture makes use of wireless sensor networks to monitor the agricultural environment. Zigbee and raspberry pi-based agriculture monitoring system serves as a reliable and efficient method for monitoring agricultural parameters. Wireless monitoring of field not only allows user to reduce the human power, but it also allows user to see accurate changes in it. It focuses on developing devices and tools to manage, display and alert the users using the advantages of a wireless sensor network system. A smart system based on precision agriculture would pave the way to a new revolution in agriculture. The user can monitor the agriculture environment from a remote location, thus providing a greenhouse condition for the plants. India being an agro based economy; precision agriculture can bring about an improvement in the primitive methods, thus developing the country stature hugely.
\end{abstract}

\section{General Terms}

Sensor networks, smart agriculture.

\section{Keywords}

Wireless Sensor Network, Sensor node, Green House

Monitoring System,Zigbee.

\section{INTRODUCTION}

Wireless technology using various sensors for precision agriculture has become a popular research with the greenhouse effect. A wireless sensor network (WSN) are spatially distributed autonomous sensors to monitor physical or environmental conditions, such as temperature, sound, pressure, etc. and to cooperatively pass their data through the network to a main location. The very traditional method is to personally go on site and monitor the agriculture. An improved system makes use of SMS, GSM based services and communication Protocols.

The proposed system is to create a fully automated agricultural monitoring system that would substantially reduce human efforts and improve the yield quality. This system provides to the crops an ideal greenhouse like environment. The sensor information can be used to make sure that the crops get just their required conditions in terms of water content, temperature, light etc.

\section{RELATED WORK}

- Kwang-il Hwang and his teammates presented a paper on the designing and implementation of wireless sensor gateway for efficient querying and managing through world wide web [1]. Here paper has presented the architecture of the sensor gateway for web-based management and its implementation details.

- Sirisha and her team presented a paper on wireless sensor based remote controlled agriculture monitoring system using zigbee [2]. The system consisted of the soil monitoring wireless sensor network and remote data center. The sensor node was developed using JN5121 module and IEEE 802.15.4/ZigBee wireless microcontroller.

- Sonali and her team published a paper on monitoring wireless sensor network using android based smart phone Application [3]. The proposed work of this project is to use the technologies of centralized computing and android programming for the development of the application.

- Prof C. H. Chavan and group presented a paper on wireless monitoring of soil moisture, temperature \& humidity using zigbee in agriculture [4]. The proposed hardware of this system includes 8 bit AVR, Blue tooth module, Temperature, humidity and soil moisture sensors, LCD. The system is low cost \& low power consuming so that anybody can afford it.

- Prabha and her group members published a paper on real-time atomization of agricultural environment for social modernization of Indian agricultural system using Arm 7 [5]. This system uses the integration of the both wired and wireless techniques and ARM controller to have regular monitoring on the environmental conditions of farm and also provides the necessary precautions to be taken for yield to increase for modern agriculture.

- $\quad$ Angel $\mathrm{C}$ and her teammate Asha $\mathrm{S}$ published a research paper on developing a smart environment in agricultural irrigation technique [6]. The paper focuses on a method for developing a smart environment to monitor the irrigational parameter in the entire field. The system also aims on reducing the energy consumption and the cost of communication.

- M.Munnira Sulthana, E.Ramakalaivani and A.V.S Elavarasi presented a paper on the topic- wireless sensor network for remote monitoring of crop field [7]. This paper presents the design and the implementation of a Wireless Sensor Network that monitors the air temperature, humidity and ambient light intensity in a crop field and from remote places.

\section{PROPOSED MODEL}

The proposed model aims at developing a smart system that would provide an ideal environment for the crops. The sensors sense the soil moisture and the humidity levels, and this information is sent via zigbee network to a remote computer. The remote computer will be capable of controlling the motor and humidity fan located on site. This reduces human effort to a great extent and also ensures that an optimal environment is provided for the crops thus improving crop quality. 


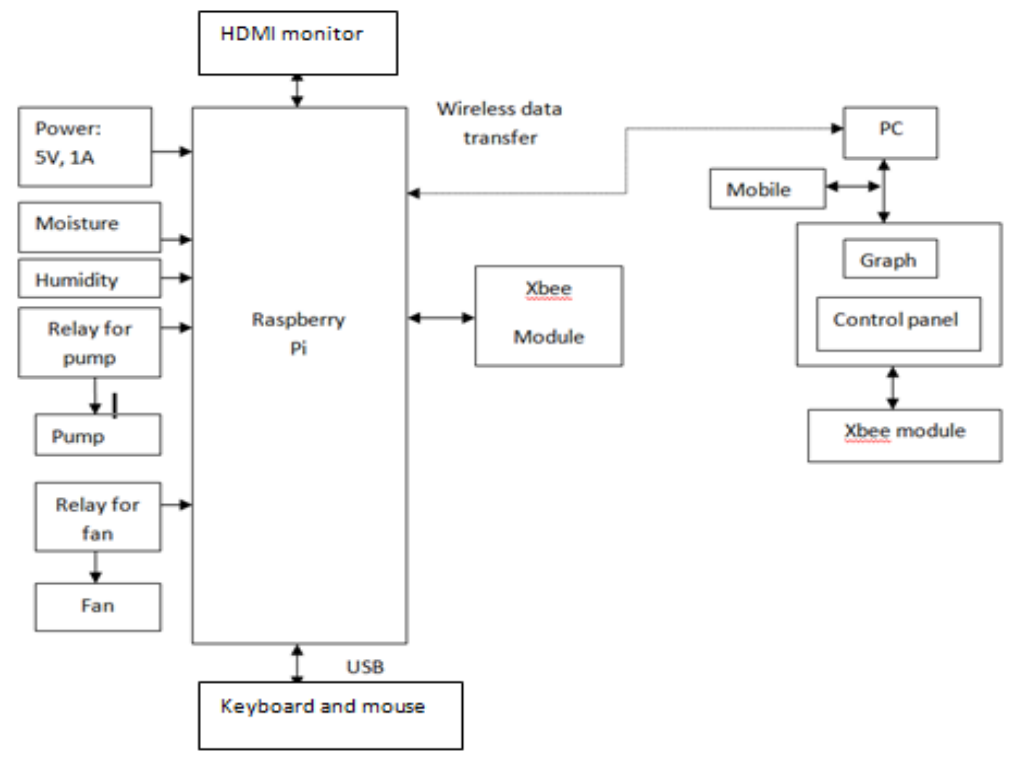

Fig 1: Block Diagram

\section{IMPLEMENTATION}

The raspberry pi forms the core unit of the setup. The pi is connected to a $5 \mathrm{~V}$ power supply externally. A keyboard and mouse also connected via the USB ports in the raspberry pi. A soil moisture sensor and a humidity sensor is connected to the setup to extract digital values. The sensor values are initially stored in the raspberry pi itself. They are then transmitted wirelessly using zigbee to another zigbee module connected to a remote computer.

The data is then transferred to the remote system using serial communication. The outputs obtained in this process are in the form of 0's and 1's. A zero output indicates that the sensor value is less than the pre defined threshold value after which, the motor and/or fan are to be switched on based on the sensor values. This function can be performed sitting at a remote location within the range of the zigbee network, thereby reducing human effort as also making sure that the plants get an ideal growth environment.

The initial step is placing the sensors, like for example in case of a moisture detection sensor, it has to be placed deep inside the soil. The sensor nodes are connected to the zigbee module which is responsible for providing a wireless communication among nodes. The raspberry pi is connected to the zigbee module thus forming a transitive link with sensor network. The processing unit is also linked via zigbee module to a display system. There are relays, valves and motors connected to the system.

\subsection{Working}

The working is as follows: The soil moisture sensor senses the moisture level. The level when reaches below permissible level, a notification is sent to user mobile. The user then can, using the smart phone app, turn on the motor. The relay helps turn on the motor and the water starts flowing out of tubes. The moisture sensor keeps a track of the moisture values every 1 minute. Each time an algorithm compares the level with the required value. Once it reaches the required level, motor automatically turns off, and a notification of the same is passed on to user.

\section{RESULTS}

The sensor data obtained from the sensors are displayed in the above user interface. A graph is plotted for the digital values of moisture and humidity. The control to the motor and fan is through the control panel in the interface. An appropriate communication port has to be selected to enable serial communication between the zigbee and the remote computer.

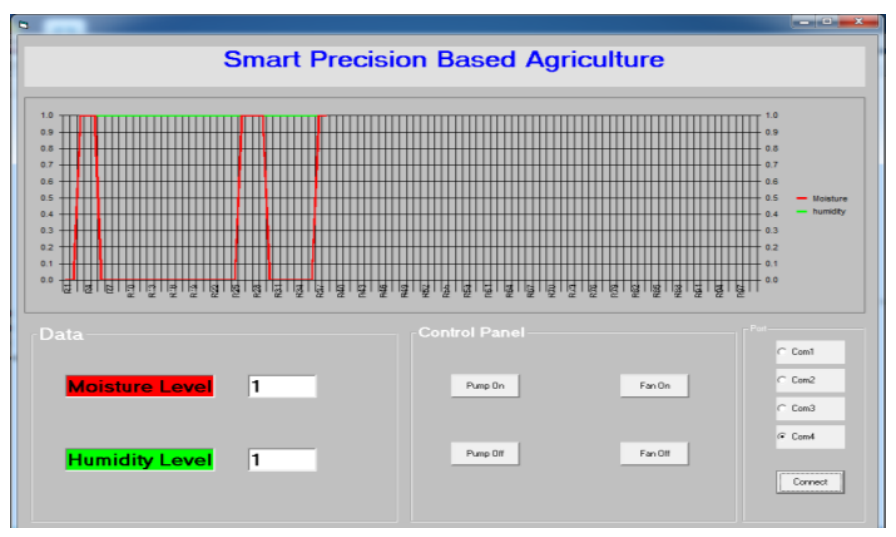

Fig: 2: User Interface

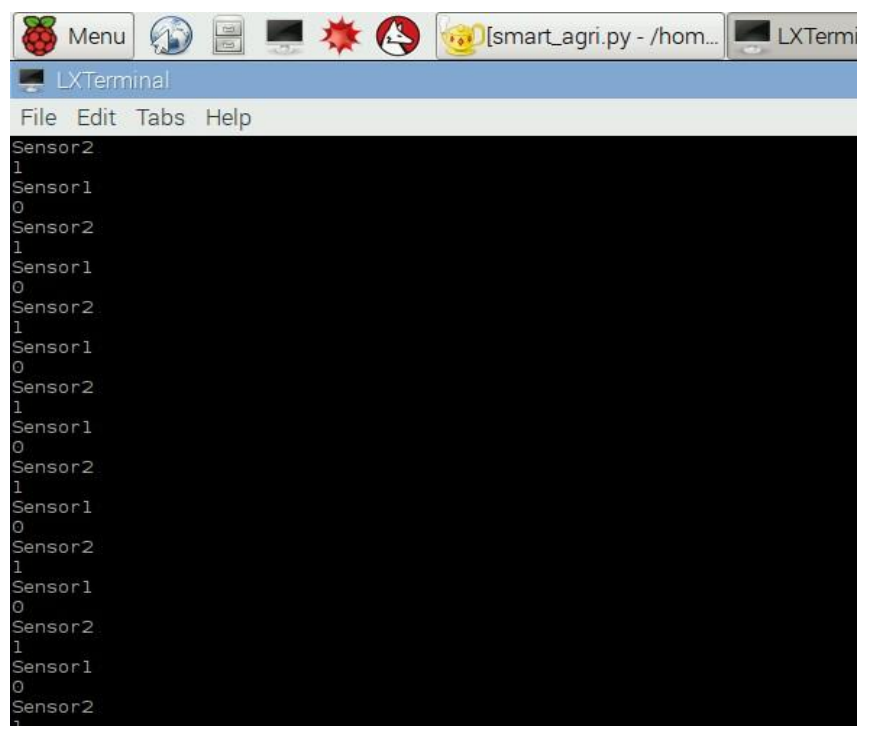

Fig. 3: Display of digital sensor values 


\section{CONCLUSION AND SCOPE}

Wireless sensor networks can help bring about a revolution in automating agriculture. This project would simplify plant monitoring process and reduced human effort drastically. User can create customized environment for the plants, thus providing them with optimal growth conditions. The scope for the project can be further widened by the use of more sensors and then storing the sensor data in the cloud enabling access from anywhere in the world. Also, an analog output instead of a digital one would help us determine accurate sensor values.

Additionally, interfacing the software with Android technology would increase its scope. The sensor values can also be converted into analog outputs. This would help getting a clear idea of the environmental condition through past records. The data can also be stored in the cloud enabling access anywhere anytime.

\section{ACKNOWLEDGMENTS}

Our sincere thanks to our guide who has contributed greatly towards development of the project.

\section{REFERENCES}

[1] Kwang-il Hwang, Jeongsik In, NhoKyung Park, Dooseop Eom:-"A Design and Implementation of Wireless Sensor Gateway for Efficient Querying and Managing through World Wide Web".

[2] Sirisha D1, B Venkateswaramma2, M Srikanth3 and A Anil Babu4 1 (Asst.Prof, ECE, Brindavan Institute of Technology \& Science, Kurnool 518001, Andhra Pradesh, India) 234(ECE, Brindavan Institute of
Technology \& Science, Kurnool 518001, Andhra Pradesh, India):- Wireless Sensor Based Remote Controlled Agriculture Monitoring System Using ZigBee.

[3] Sonali Tembekar, Amit Saxena Dept. Computer Science of Engineering TRUBA Institute of Engineering and Information Technology Bhopal, India Dept. :Monitoring Wireless Sensor Network using Android based Smart Phone Application.

[4] Prof C. H. Chavan, Mr.P. V.Karande Department of Electronics \& Telecommunication Aditya Engineering College Beed, Maharashtra,India:- Wireless Monitoring of Soil Moisture, Temperature \& Humidity Using Zigbee in Agriculture.

[5] Prabha1 , Tanujabai J.M2 , S. Krupesh3 Assistant professor, Dept. of ECE,BITM, Bellary, Karnataka, India1 PG Student [VLSI \& Embedded System], Dept. of ECE,BITM, Bellary, Karnataka, India2 UG Student [ECE] , Dept. of IT,PDIT College, Karnataka, India3:Real-Time Atomization of Agricultural Environment for Social Modernization of Indian Agricultural System Using Arm 7

[6] Angel C and Asha S, School of Computing Science and Engineering, VIT University, Chennai, Tamil Nadu:Asmart environment in agricultural irrigation technique.

[7] M.Munnira Sulthana, E.Ramakalaivani, A.V.S. Elavarasi , Assistant Professor, Karpagam College Of Engineering, Coimbatore, India:- Wireless sensor network for remote monitoring of crop field. 